\title{
Assessing the effectiveness of green infrastructures on urban flooding reduction: A community scale study
}

\author{
Wen Liu, Weiping Chen*, Chi Peng \\ State Key Laboratory for Urban and Regional Ecology, Research Center for Eco-Environmental Sciences, Chinese Academy of Sciences, Beijing 100085 China
}

\section{A R T I C L E I N F O}

\section{Article history:}

Received 23 January 2014

Received in revised form 14 July 2014

Accepted 14 July 2014

Available online 5 August 2014

\section{Keywords:}

Green infrastructure

Storm water runoff

Runoff volume

Peak flow

Reduction effects

Community

\begin{abstract}
A B S T R A C T
The risk of urban flooding is increasing as a result of rapid urbanization. Green infrastructure (GI) is an emerging planning and design concept to mitigate urban flooding. A community scale simulation model was developed to quantify the effectiveness of GI on reducing the volume and peak flow of urban flooding. Five scenarios, namely expanding green space, converting to concave green space, constructing a runoff retention structure, converting to porous brick pavement, and combining previous four measures were considered for an urban community in Beijing. The outcomes showed that the model performed responsively to simulate the storm runoffs at varying recurrence intervals under these scenarios. Simulation results showed that, the impervious surfaces have the most contribution to the storm runoffs of the community. The reduction capacity for single GI facility was limited, especially in bigger storm events. The integrated GI configuration has effective reduction percentage, such as the total runoff reduction was ranged from $100 \%$ to $85.0 \%$ and the peak flow reduced $100-92.8 \%$. This work can guide local planners and decision makers in their actions on green infrastructures in community scale.
\end{abstract}

(C) 2014 Elsevier B.V. All rights reserved.

\section{Introduction}

Over half of the people worldwide now live in cities and the percentage is expected to reach eighty by 2050 (Bettencourt and West, 2010). It causes the shortage of natural resources and creates stresses in the already stressed out urban ecosystems (Mentens et al., 2006). As the impervious urban surfaces expanding, crop lands, pastures, wilderness, and forests are displaced by dwellings, office structures, streets, highways, and industrial and commercial establishments. Significant land use modifications that converted the natural landscape to urban settings may have disastrous consequences for urban ecosystems. Impervious surfaces alter the hydrological nature of surface runoffs, prevent the infiltration of surface water into the ground, greatly increase storm runoffs in terms of volumes and peak flow (Goonetilleke et al., 2005; Whitford et al., 2001), and consequently causing floods in cities. The urban flooding endangers life, private properties and public infrastructures, erodes stream banks and channels, and contaminates streams and rivers in urban areas. Urban flooding risk may be intensified as the earth experiences more frequent weather extremes with the global climate change (Foster et al., 2011; Villarreal et al., 2004).

\footnotetext{
* Corresponding author. Tel.: +86 1062843981 ; fax: +86 1062918177.

E-mail address: wpchen@rcees.ac.cn (W. Chen).
}

Conventionally, storm water is detaining and conveying through piped drainage systems. However, the conventional approaches fail to address the increases of storm runoff volume and peak flows caused by urban development. The runoffs overburdened the municipal wastewater treatment works and carried pollutants such as trash, bacteria and heavy metals into the receiving waters that degraded the quality of the urban streams. The holistic modeling and ecological risk assessment of urban ecosystems can be used for risk evaluation and urban management to minimize the damage by extreme weather and changing climate from the source of urban flooding (Chen et al., 2013, 2014). In recent years, the green infrastructure (GI) has been widely used in many cities in the USA, and in the UK, Canada, Germany and New Zealand to mitigate urban flooding (Ahiablame et al., 2012). The GI employs principles such as preserving and recreating natural landscape features, implementing some on-site infrastructures that work with nature to reduce the storm water runoff from sources (Graham et al., 2004). It is an economically and environmentally viable approach for developing sustainable and resilient communities, adapting climate change, as well as for promoting smart growth and urban sustainability (Benedict and McMahon, 2002, 2006; Dunn, 2010; Foster et al., 2011; Gill et al., 2007; Mell, 2009).

The GI installations consist of systems and practices that utilize or mimic the natural processes, allowing storm water to infiltrate, evaporate, runoff, and/or be used on-site. For example, reservoirs and ponds may be strategically placed on the flow paths to 


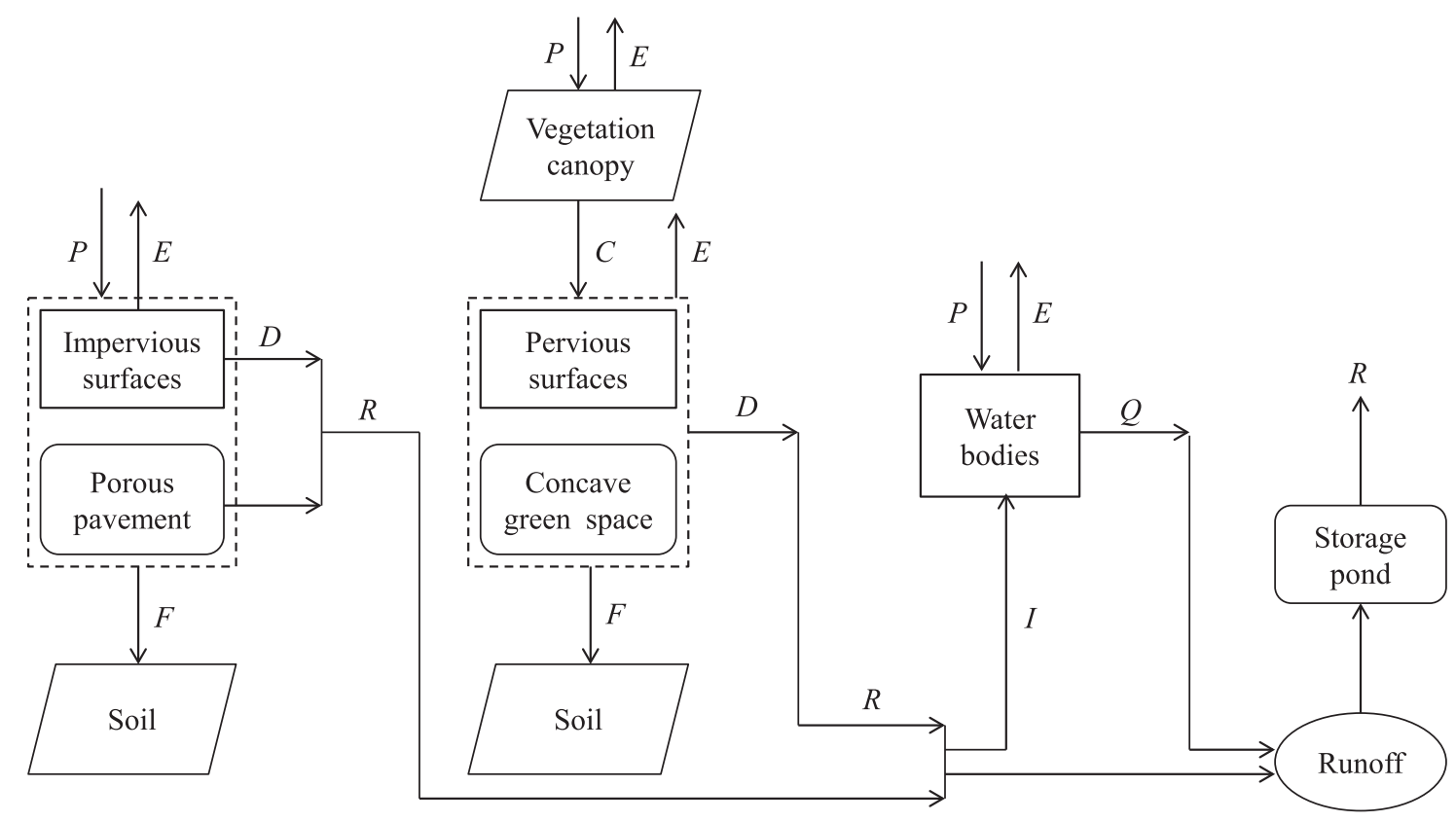

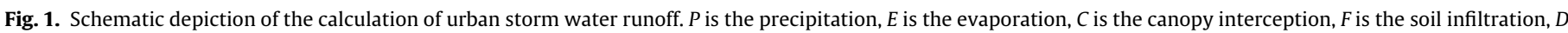
is the depression, $I$ is the inflow, $Q$ is the outflow, $R$ is the surface runoff.

temporary store the surface runoff (Ferguson, 1998; White, 2002) and green spaces where runoff diverted from impervious surfaces may have a chance to infiltrate and/or evaporate (Mentens et al., 2006). GI can be used in a wide range of landscape scales in place of or in addition to traditional storm runoff control elements, as well as maintain or restore an urban ecosystem's hydrologic and ecological functions. Therefore, for effective control of urban flooding, it is imperative to develop tools that optimize the GI configurations according to the urban hydrologic cycle.

The hydrological performance and benefits of GI practices have been shown in numerous studies on laboratory scales, in-situ scales and micro-scales. For example, Alfredo et al. (2009) found that green roofs can delay and prolong the roof discharge and reduce its peak rate by $30-78 \%$ compared to a standard roof surface. Dreelin et al. (2006) showed that porous pavements reduced 93\% of runoff on two parking lots, and it can be used to control small storms (less than $2 \mathrm{~cm}$ ). Schneider and McCuen (2006) showed that the effects of cisterns on peak discharge reduction are ineffective for large storms, but very effective for small storms. Chapman and Horner (2010) reported that a street-side bioretention facility in Washington can achieve $26-52 \%$ of runoff retention in real-weather conditions. Qin et al. (2013) concluded that the swale, permeable pavement and green roof are more effective in flood reduction during heavier and shorter storm events compared with the conventional drainage system.

Influences of GI on urban storm runoff reduction can be evaluated by hydrological models such as Storm Water Management Model (SWMM), Urban Volume and Quality (UVQ) and Model for Urban Stormwater Improvement Conceptualisation (MUSIC) (Huber et al., 1988; MUSIC Development Team, 2003; Mitchell et al., 2003). However, these traditional hydrological models are cumbersome and unsuitable to evaluate the effectiveness of GI in mitigating urban flooding because of the difficulties in defining model parameters and the over-simplifications of reactive processes related to GI. Although the GI performance on reducing urban flooding has been extensively investigated, few studies have attempted to examine and compare the reduction effectiveness between integrated GI configuration and single GI facilities under different storm recurrence periods.
In this research, a simple rainfall-runoff model with fewer parameters requirements is developed to describe functions of green infrastructures based on the water mass balance through the processes of urban hydrological cycle. By using the model, the effectiveness of single GI facilities and the integrated GI configuration on urban flooding reductions were evaluated under different storm recurrence periods. A typical community in Beijing is selected for study. This study illustrates a scientifically and ecologically responsible approach for urban storm runoff management and landscape planning.

\section{Methodology}

In terms of precipitation and runoff, the urban area is divided into four types of surfaces, namely impervious surface (building footprints, roads, pavements, parking lots, etc.), pervious surface (green spaces, lawns, bare soils, etc.), water body (natural and man-made reservoirs, wetlands and rivers), and green infrastructures (Fig. 1). In a precipitation event, the rain would be routed through different processes of the hydrological cycle in each surface, which are depended on the nature of surfaces and dynamic factors. The water routing through each compartment is calculated independently and then sum up the three surfaces' runoffs or the overflows of GIs to obtain the total storm runoff. The impacts of green infrastructures on storm water infiltration, retention and storage capacity are accounted for in calculating storm runoff. The model subroutines are described in the following sections. Based on water mass balance, the storm runoff volume calculation is obtained by selecting simpler calculation equations with fewer parameters from several typical urban drainage models. The reservoir routing is neglected in the peak flows calculations due to the micro-scale of the community.

\subsection{Runoff of impervious surface}

The calculation of impervious surface runoff is based on the water balance (Mitchell et al., 2003). Rainfall reaches impervious areas beyond the depression storage depth is directly converted to 
surface runoff. The equation to calculate the amount of runoff from impervious surface $\left(R_{\mathrm{imp}}, \mathrm{mm}\right)$ is:

$R_{\mathrm{imp}}= \begin{cases}P-(D-S T)-E_{\mathrm{D}} & P-E_{\mathrm{D}}>D-\mathrm{ST} \\ 0 & P-E_{\mathrm{D}} \leq D-\mathrm{ST}\end{cases}$

$E_{D}=\min \left(E_{p}, S T\right)$

where $P$ is the precipitation ( $\mathrm{mm}$ ), $D$ the depression of impervious area, ST the depression storage level $(\mathrm{mm}), E_{\mathrm{D}}$ the evaporation of depression ( $\mathrm{mm}$ ), and $E_{\mathrm{p}}$ is the potential evaporation $(\mathrm{mm})$ of the simulated time step.

\subsection{Runoff process of pervious surface}

Four processes, namely interception, evaporation, infiltration and depression, are considered simultaneously in simulating runoffs of pervious surface and calculated in order. Precipitation entering the pervious areas, firstly intercepted by vegetation canopy, then the net rainfall reaches the ground to permeate and be stored in the soil, and only water excesses the depression storage is routed as runoff. The evaporation was occurred to recover the interception and depression water storage. Based on the water balance, the pervious runoff was equal to the rainfall minus the loss amounts of interception, evaporation, infiltration and depression water.

\subsubsection{Interception}

The vegetation interception routine is based on the algorithm of UFORE-hydro that simplifies the explicit simulation of canopy drainage performed in the Rutter model to reduce model parameter requirements (Wang et al., 2008). The equation to calculate water retained by vegetation canopy interception $\left(\mathrm{SI}_{\mathrm{c}}, \mathrm{mm}\right)$ is:

$\mathrm{SI}_{\mathrm{c}}= \begin{cases}\mathrm{SI}_{0}+P-P_{\mathrm{f}}-E_{\mathrm{c}} & \mathrm{SI}_{0}+P-P_{\mathrm{f}}-E_{\mathrm{c}} \leq S_{\mathrm{c}} \\ S_{\mathrm{c}}-E_{\mathrm{c}} & \mathrm{SI}_{0}+P-P_{\mathrm{f}}-E_{\mathrm{c}}>S_{\mathrm{c}}\end{cases}$

where $\mathrm{SI}_{0}$ is the water storage of interception during the prior time interval $(\mathrm{mm}), E_{\mathrm{c}}$ the evaporation of leaf interception $(\mathrm{mm})$ and $P_{\mathrm{f}}$ is the free throughfall without contacting canopy $(\mathrm{mm})$ which may be calculated by:

$P_{\mathrm{f}}=P \mathrm{e}^{-\kappa \mathrm{LAI}}$

$E_{\mathrm{c}}=\left(\frac{\mathrm{SI}_{\mathrm{c}}}{S_{\mathrm{c}}}\right)^{2 / 3} E_{\mathrm{p}}$

$S_{\mathrm{C}}=S_{\mathrm{L}} \mathrm{LAI}$

where $\kappa$ is an extinction coefficient, LAI the leaf area index, $S_{\mathrm{c}}$ the storage capacity of canopy $(\mathrm{mm})$ and $S_{\mathrm{L}}$ denotes the specific leaf storage ( $\mathrm{mm})$.

\subsubsection{Evaporation}

The evaporation process is commonly simulated by the PenmanMonteith equation that requires many locale-specific parameters often difficult to reliably define. Instead, we choose Hargreaves and Samani (1985) that simulates the evaporation process using only the air temperatures. The equation for calculating potential evaporation $\left(E_{\mathrm{p}}, \mathrm{mm} / \mathrm{d}\right)$ is given as:

$E_{\mathrm{p}}=0.0023 \times 0.408\left(\frac{\mathrm{RA}_{\max }}{\lambda}\right)\left(T_{\max }-T_{\min }\right)^{0.5}\left(T_{\mathrm{av}}+17.8\right)$

where $R A_{\max }$ is the extraterrestrial radiation of the surface related to latitude $\left(\mathrm{MJ} / \mathrm{m}^{2} / \mathrm{d}\right), \lambda$ the latent heat of vapor $(\mathrm{MJ} / \mathrm{kg}$ ) which is usually $2.45 \mathrm{MJ} / \mathrm{kg}, T_{\max }$ the maximum daily temperature $\left({ }^{\circ} \mathrm{C}\right)$, $T_{\min }$ the minimum daily temperature $\left({ }^{\circ} \mathrm{C}\right)$ and $T_{\mathrm{av}}$ is the average daily temperature $\left({ }^{\circ} \mathrm{C}\right)$. The constant 0.408 is used to convert the radiation to evaporation equivalents in $\mathrm{mm}$ (Droogers and Allen, 2002).

\subsubsection{Infiltration}

The Green-Ampt infiltration equation modified by Mein and Larson (Mein and Larson, 1973) is used to simulate the infiltration process, which is a function of the soil suction head, porosity, hydraulic conductivity and time. The infiltration rate $(f, \mathrm{~mm} / \mathrm{min})$ is calculated by

$f=\left\{\begin{array}{cc}K_{\mathrm{s}}\left[1+\left(\theta_{\mathrm{s}}-\theta_{i}\right) S_{\mathrm{f}} / F\right] & t>t_{\mathrm{p}} \\ i & t \leq t_{\mathrm{p}}\end{array}\right.$

$t_{\mathrm{p}}=\frac{F_{\mathrm{p}}}{i}$

$F_{\mathrm{p}}=\frac{\left(\theta_{\mathrm{s}}-\theta_{i}\right) S_{\mathrm{f}}}{i / K_{\mathrm{s}}-1}$

where $K_{\mathrm{s}}$ is the saturated hydraulic conductivity ( $\left.\mathrm{mm} / \mathrm{min}\right), \theta_{\mathrm{s}}$ the saturated water content (\%), $\theta_{\mathrm{i}}$ the initial water content $(\%), S_{\mathrm{f}}$ the suction at wetting front $(\mathrm{mm})$ and $F$ is the cumulative depth of infiltration $(\mathrm{mm})$. The depth infiltrated at that moment $\left(F_{\mathrm{p}}\right)$ is given by setting $f=i$ in Eq. (4-a) and solving for $F_{\mathrm{p}} \cdot t_{\mathrm{p}}$ is the onset of surface ponding ( $\mathrm{min}), i$ is the net rainfall intensity $(\mathrm{mm} / \mathrm{min})$ which can be calculated as:

$i=\frac{\left[P-\left(\mathrm{SI}_{\mathrm{c}}-\mathrm{SI}_{0}\right)\right]}{\Delta t}$

where $\Delta t$ is the simulated time step.

\subsubsection{Depression storage}

The empirical equation of Linsley et al. (1949) is used to simulate the depression storage process. The depression storage $\left(\mathrm{Sd}_{0}, \mathrm{~mm}\right)$ at the initial time step is calculated as:

$\mathrm{Sd}_{0}=\mathrm{Sd}_{\max }\left(1-\exp \left(-\frac{\mathrm{PC}}{\mathrm{Sd}_{\max }}\right)\right)$

where $\mathrm{Sd}_{\max }$ is the depression of pervious area $(\mathrm{mm})$ and $\mathrm{PC}$ is the accumulated residual rainfall $(\mathrm{mm})$, which represents rainfall minus the interception and infiltration. The calculation of depression in the next time step $(\mathrm{Sd}, \mathrm{mm})$ is based on mass balance:

$\mathrm{Sd}= \begin{cases}\mathrm{PC}+\mathrm{Sd}_{t}-E_{\mathrm{S}} & \mathrm{PC}+\mathrm{Sd}_{t}-E_{\mathrm{s}}<\mathrm{Sd}_{\max } \\ 0 & \mathrm{PC}+\mathrm{Sd}_{t}-E_{\mathrm{s}} \geq \mathrm{Sd}_{\max }\end{cases}$

$E_{\mathrm{s}}=\min \left(\mathrm{Sd}_{t}, E_{\mathrm{p}}\right)$

where $S d_{t}$ is the depression in the previous time step (mm) and $E_{\mathrm{s}}$ is the evaporation of pervious depression ( $\mathrm{mm}$ ).

According to water balance, the runoff volume from the pervious surface of unit area in each time step $\left(R_{\mathrm{per}}, \mathrm{mm}\right)$ may be calculated as:

$R_{\text {per }}=P-\left(\mathrm{SI}_{\mathrm{c}}-\mathrm{SI}_{0}\right)-f \times \Delta t-\mathrm{Sd}-E_{\mathrm{S}}$ 


\subsection{Water body outflow simulation}

The water bodies are devices where water may be temporarily or permanently stored. Based on water balance, the outflow from water bodies $\left(Q_{w}, \mathrm{~m}^{3}\right)$ is calculated by:

$Q_{\mathrm{w}}= \begin{cases}0, & \left(\frac{A_{\mathrm{p}}}{A-A_{\mathrm{c}}}\right)\left(\alpha R_{\mathrm{imp}}+\beta R_{\mathrm{per}}\right) A+\left(P-E_{\mathrm{w}}\right) \times A_{\mathrm{c}} \leq H-V_{\mathrm{w}} \\ \left(\frac{A_{\mathrm{p}}}{A-A_{\mathrm{c}}}\right)\left(\alpha R_{\mathrm{imp}}+\beta R_{\mathrm{per}}\right) A+\left(P-E_{\mathrm{w}}\right) \times A_{\mathrm{c}}-H+V_{\mathrm{w}}, & \left(\frac{A_{\mathrm{p}}}{A-A_{\mathrm{c}}}\right)\left(\alpha R_{\mathrm{imp}}+\beta R_{\mathrm{per}}\right) A+\left(P-E_{\mathrm{w}}\right) \times A_{\mathrm{c}}>H-V_{\mathrm{w}}\end{cases}$ where $A_{\mathrm{p}}$ is the rainwater of catchment area that flows into the water body $\left(\mathrm{m}^{3}\right), A$ the area of the community $\left(\mathrm{m}^{2}\right), A_{\mathrm{c}}$ the surface area of the water body $\left(\mathrm{m}^{2}\right), \alpha$ the percentage of impervious areas (\%), $\beta$ the percentage of pervious areas (\%), $E_{\mathrm{w}}$ the evaporation of water surface $(\mathrm{mm})$ estimated by potential evaporation, $H$ the water storage capacity of water body $\left(\mathrm{m}^{3}\right)$ and $V_{\mathrm{w}}$ is the storage level of water body before rain $\left(\mathrm{m}^{3}\right)$. The infiltration process is not considered in the calculation as most urban water bodies have seepage prevention measures.

Thus, the runoff volume at each time step interval in the community $\left(R, \mathrm{~m}^{3}\right)$ is:

$R=\left(1-\frac{A_{\mathrm{p}}}{A-A_{\mathrm{c}}}\right)\left(\alpha R_{\mathrm{imp}}+\beta R_{\mathrm{per}}\right) A+Q_{\mathrm{w}}$

The total storm water runoff volume in the community is the sum of the runoff at each time step interval.

\subsection{Green infrastructures simulation}

Green infrastructures include wetlands, ponds, swales, rainwater tanks, vegetated filter strips, and filter strips. These infrastructures each retains a specified amount of rain "on-site", in storage devices or through groundwater recharge. In this study, we selected three typical green infrastructures, which are more suitable for implementing in communities of China, including storage pond, concave green space and permeable brick pavement to evaluate their storm runoff regulatory functions. The overflow calculation of GI is that substituted the corresponding surfaces then accordingly connected the runoff calculation through coupling with hydrological processes.

The storage pond implemented near the storm water drainage outlet of the community, it can temporally storage the total runoff and reduce runoff discharge. The outflow from a storage pond $\left(Q_{r}\right.$, $\mathrm{m}^{3}$ ) is calculated by

$Q_{\mathrm{r}}= \begin{cases}\mu R_{\mathrm{c}}-\left(H_{\mathrm{r}}-V_{\mathrm{r} 0}\right) & \mu R_{\mathrm{c}}>H_{\mathrm{r}}-V_{\mathrm{r} 0} \\ 0 & \mu R_{\mathrm{c}} \leq H_{\mathrm{r}}-V_{\mathrm{r} 0}\end{cases}$

where $\mu$ is the rainwater collection ratio (\%), $R_{\mathrm{c}}$ the accumulated runoff at time step $\left(\mathrm{m}^{3}\right), H_{\mathrm{r}}$ the water storage capacity of the storage pond $\left(\mathrm{m}^{3}\right)$ and $V_{\mathrm{r} 0}$ is the water volume of the storage pond prior to rain $\left(\mathrm{m}^{3}\right)$. The runoff volume under the storage pond configuration $\left(R_{\mathrm{r}}, \mathrm{m}^{3}\right)$ is expressed as:

$R_{\mathrm{r}}=(1-\mu) R+Q_{\mathrm{r}}$

The function of concave green space is similar to swale, which retains storm water inside, increase infiltration and prevents the runoff flowing to the adjacent road surfaces. Assume all the pervious areas (green spaces) are reformed concave green spaces. The runoff from concave green space $\left(Q_{s}, \mathrm{~m}^{3}\right)$ is calculated by

$Q_{\mathrm{s}}= \begin{cases}\left(i \Delta t+q-f_{\mathrm{s}}-(1 / 2) h_{\mathrm{s}}\right) \beta A & i \Delta t+q-f_{\mathrm{s}}>(1 / 2) h_{\mathrm{s}} \\ 0 & i \Delta t+q-f_{\mathrm{s}} \leq(1 / 2) h_{\mathrm{s}}\end{cases}$

where $q$ is the storage level on the concave green space of the previous time interval $(\mathrm{mm}), f_{\mathrm{s}}$ the infiltration of the concave green space $(\mathrm{mm})$ and $h_{\mathrm{s}}$ is the depth of concave green space $(\mathrm{mm})$. The runoff volume under the concave green space configuration $\left(R_{\mathrm{S}}\right.$, $\mathrm{m}^{3}$ ) is expressed as:

$R_{s}=\left(1-\frac{A_{p}}{A-A_{c}}\right)\left(A \cdot \alpha R_{\text {imp }}+Q_{s}\right)+Q_{w}$
Porous pavement is designed to temporarily store surface runoff, allowing slow infiltration into the subsoil. The infiltration functions of impervious surface may be restored by replacing it with porous pavement, such as permeable bricks with cushion layers of gravel underneath. The permeable bricks are precast concrete block with open voids to allow for infiltration. The runoff from the porous brick pavement $\left(Q_{\mathrm{p}}, \mathrm{m}^{3}\right)$ is calculated by

$Q_{\mathrm{p}}= \begin{cases}\left(P-\eta \Delta t+F_{\mathrm{c}}-H_{\mathrm{p}}\right) \alpha A \omega & P-\eta \Delta t+F_{\mathrm{c}}>H_{\mathrm{p}} \\ 0 & P-\eta \Delta t+F_{\mathrm{c}} \leq H_{\mathrm{p}}\end{cases}$

where $\eta$ is the infiltration rate of subsoil $(\mathrm{mm} / \mathrm{min}), F_{\mathrm{c}}$ the accumulated water content volume of subsoil $(\mathrm{mm}), H_{\mathrm{p}}$ the water storage capacity of porous brick pavement $(\mathrm{mm})$ and $\omega$ is the proportion of porous brick pavement to impervious area. The runoff volume of the porous brick pavement configuration $\left(R_{\mathrm{p}}, \mathrm{m}^{3}\right)$ is expressed as:

$R_{\mathrm{p}}=\left(1-\frac{A_{\mathrm{p}}}{A-A_{\mathrm{c}}}\right)\left(\alpha A(1-\omega) R_{\mathrm{imp}}+Q_{\mathrm{p}}+R_{\mathrm{per}}\right)+Q_{\mathrm{w}}$

\section{Model parameters and simulation scenarios}

A community in Haidian district of Beijing is selected as a case to study impacts of green infrastructures on urban flooding reduction. The community is $54,783 \mathrm{~m}^{2}, 30 \%$ of that is pervious green area covered by grasses and the remaining area is impervious surfaces of streets, pavements, and structures. This community does not have receiving water body. It represents as a typical new built community in Beijing. Table 1 summarizes the parameter values used for the model simulation and their sources.

The total storm runoff volume and peak flow under different storm events and green infrastructure configuration are simulated. Four storm events representing 1, 2, 5 and 10 year of recurrence intervals are selected. The 24-h rainfalls for the events are 45.6, $72.0,115.2$, and $158.3 \mathrm{~mm}$, respectively. The patterns of the precipitation events are modeled according to the storm intensity formula of Beijing and Pearson type III curve.

Five green infrastructure configurations are considered: (1) increasing green space area from $30 \%$ to $40 \%$; (2) constructing a $1500 \mathrm{~m}^{3}$ storage pond; (3) changing green area from flat to concaved with 5 -cm depth; (4) converting $50 \%$ of impervious area into the porous brick pavement; (5) combining the configurations of previous four. The reductions of runoff volumes and peak flows by implementing the GI configurations are evaluated and compared with the outcomes of no GI practice (i.e., base scenario). The simulation runs at a 5-min time step on the basis of storm inputs.

\section{Results and discussion}

\subsection{Runoff and peak flow under different storm events}

The rainfall (input) and the model predicted runoff (output) hydrographs of 1-year storm recurrence interval under the base scenario is used to illustrate the behaviors of precipitation vs. runoff (Fig. 2). The dynamics of storm runoff were coherent with storm 
Table 1

Parameters for the model simulation.

\begin{tabular}{|c|c|c|c|}
\hline Parameters & Values & Units & Source \\
\hline \multicolumn{4}{|l|}{ Community's characters } \\
\hline Total area & 54,783 & $\mathrm{~m}^{2}$ & Based on local investigation \\
\hline Percentage of impervious areas & 70 & $\%$ & Based on local investigation \\
\hline Percentage of pervious areas & 30 & $\%$ & Based on local investigation \\
\hline Water bodies area & 0 & $\mathrm{~m}^{2}$ & Based on local investigation \\
\hline Water storage capacity of water body & 0 & $\mathrm{~m}^{3}$ & Based on local investigation \\
\hline \multicolumn{4}{|l|}{ Green infrastructures characters } \\
\hline Water storage capacity of storage pond & 1500 & $\mathrm{~m}^{3}$ & Assumed \\
\hline Rainwater collection ratio & 100 & $\%$ & Assumed \\
\hline Depth of concave green space & 50 & $\mathrm{~mm}$ & Assumed \\
\hline Infiltration rate of subsoil & 0.3 & $\mathrm{~mm} / \mathrm{min}$ & Wang (2007) \\
\hline Water storage capacity of porous brick pavement & 32.86 & $\mathrm{~mm}$ & Wang (2007) \\
\hline \multicolumn{4}{|l|}{ Meteorological conditions } \\
\hline Maximum daily temperature & 31 & ${ }^{\circ} \mathrm{C}$ & Beijing meteorological data \\
\hline Minimum daily temperature & 22 & ${ }^{\circ} \mathrm{C}$ & Beijing meteorological data \\
\hline Average daily temperature & 26.5 & ${ }^{\circ} \mathrm{C}$ & Beijing meteorological data \\
\hline \multicolumn{4}{|l|}{ Soil properties } \\
\hline Saturated hydraulic conductivity & 0.144 & $\mathrm{~mm} / \mathrm{min}$ & Xie et al. (1998) \\
\hline Wetting front suction & 69.696 & $\mathrm{~mm}$ & Fu et al. (2002) \\
\hline Saturated water content & 40.627 & $\%$ & Xie et al. (1998) \\
\hline Initial water content & 26.279 & $\%$ & Xie et al. (1998) \\
\hline \multicolumn{4}{|l|}{ Vegetation characters } \\
\hline Leaf area index & 3.85 & - & Su and Xie (2003) \\
\hline Extinction coefficient & 0.3 & - & Wang et al. (2008) \\
\hline Special leaf storage & 0.2 & $\mathrm{~mm}$ & Wang et al. (2008) \\
\hline \multicolumn{4}{|l|}{ Runoff yield parameters } \\
\hline Depression of impervious area & 3 & $\mathrm{~mm}$ & $\mathrm{Xu}(1998)$ \\
\hline Depression of pervious area & 4 & $\mathrm{~mm}$ & Lei et al. (2010) \\
\hline
\end{tabular}

events, suggesting the model is capable of simulating the hydrological processes. Under 1-, 2-, 5-, and 10-year storm return intervals, the maximum storm intensities were $0.9,1.9,2.5$ and $2.8 \mathrm{~mm} / \mathrm{min}$, respectively, resulting in peak runoff flows of 47.3, 97.8, 131.1 and $152.4 \mathrm{~m}^{3} / \mathrm{min}$. As the intensity increased, the peak runoff increased from $91.9 \%$ to $97.9 \%$ of the maximum rainfall, respectively for the four storm events.

The temporal changes of accumulative runoff under the 1-, 2-, 5-, and 10-year storm recurrence intervals on base scenario are illustrated in Fig. 3. The runoff volumes were 1546.9, 2813.3, 4858.0, and $6894.8 \mathrm{~m}^{3}$ under the 1-, 2-, 5-, and 10-year storm recurrence intervals respectively. The runoff volume ratio increased from $61.9 \%$ to $79.5 \%$ with the storm intensity increased from 1 - to 10 -year recurrence periods.

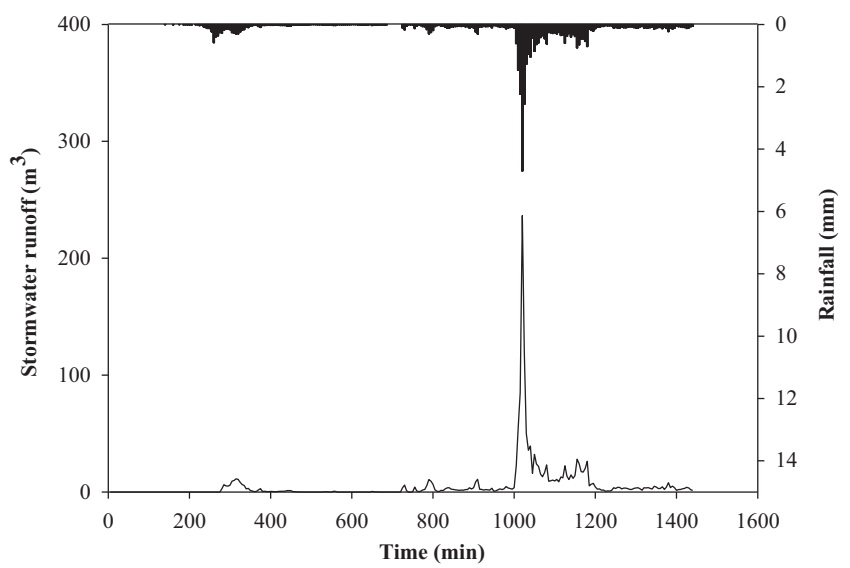

Fig. 2. Dynamic changes of rainfall versus runoff simulation of 1-year recurrence interval storm.
The model simulations track the water balance of storm events through processes including interception, infiltration, evaporation, depression-storage, and runoffs from impervious and pervious areas (Fig. 4). In this case, runoffs from the impervious area which occupied $70 \%$ of the total surface accounted for $58.6 \%$ to $66.8 \%$ of the total precipitation. Runoffs from the pervious area (30\% of the total surface) were considerably lesser and accounted for $3.3-12.7 \%$ of the precipitation also depending on the storm recurrence periods. Infiltration and evaporation were important processes of the urban runoff hydrology. Proportional to storm intensities, infiltration and evaporation ranged inversely from 25.4 to $16.6 \%$ and $10.0 \%$ to $2.9 \%$, respectively. The loss through vegetation canopy interception and depressions were minor, accounting for $0.5-0.2 \%$ and $2.1-0.8 \%$, respectively.

The runoff generation ratios of impervious area, from $83.8 \%$ to $95.4 \%$, were larger than those of the pervious area, from $10.9 \%$ to $42.4 \%$. It indicated that the impervious surfaces not only have the largest footprint, but also have the most contribution to the storm runoffs of the community. Installing green infrastructures and/or increasing green spaces would have a profound impact on mitigating urban flooding.

\subsection{Green infrastructures impacts on storm runoff volume and peak flow}

\subsubsection{Green space}

If the green spaces in the community were converted to impervious surfaces through urban expansions, the runoff volumes would be $2093.3,3538.6,5903.7$, and $8273.7 \mathrm{~m}^{3}$, and peak flows would be $51.3,101.7,134.5$ and $155.4 \mathrm{~m}^{3} / \mathrm{min}$ under $1-, 2-, 5-$, and $10-$ year storm events, respectively. Compared with the outcomes of the base scenario, the runoff volumes increased $35.3-20.0 \%$, and the peak flows have increased $8.4-2.0 \%$, respectively. With the 

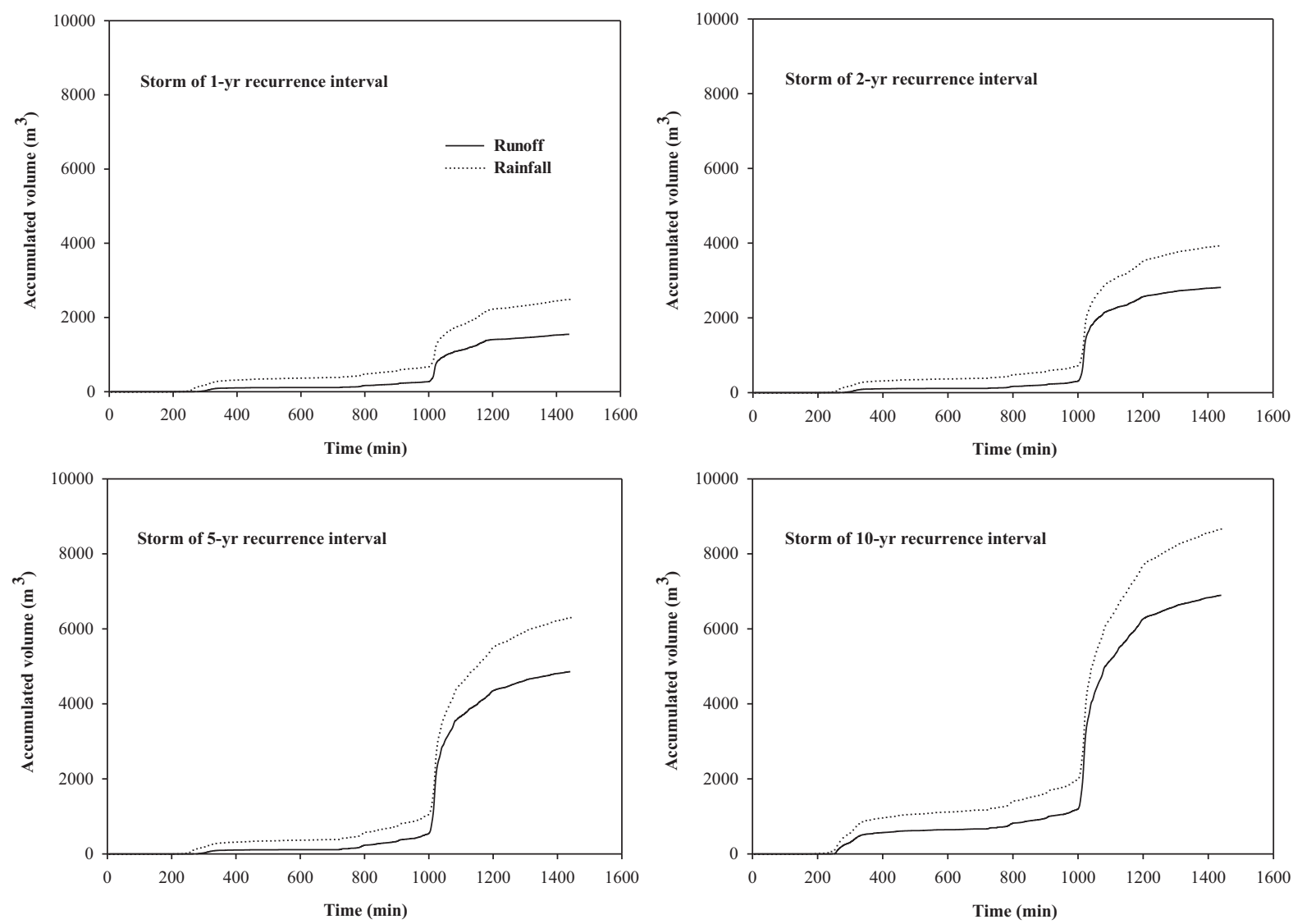

Fig. 3. Cumulative rainfall versus runoff, storms of 1-, 2-, 5-, and 10-year recurrence intervals.

conversion, the community would become more susceptible to water logging and flooding.

If the green area of the community was expanded from the existing $30-40 \%$ of the surfaces, comparing to those of the base scenario, the runoff volumes would be reduced $11.8-6.7 \%$, and the peak flows would be $46.0,96.6,129.9$ and $151.4 \mathrm{~m}^{3} / \mathrm{min}$ that suggested $2.8-0.7 \%$ reductions respectively under the $1-, 2-, 5-$, and 10-year storm events (Fig. 5A). When the green space further increases to $50 \%$ of the surfaces, the runoff volumes would be reduced 23.6-13.3\%, and the peak flows would become 44.7, 95.3,
128.8 and $150.4 \mathrm{~m}^{3} / \mathrm{min}$, reduced $5.6-1.3 \%$ respectively under $1-$, 2-, 5-, and 10-year storm events.

These results indicated that the reduction effectiveness of green space increase was relatively small in terms of storm runoff volume and peak flow under all storm events. Thus, the urban flooding could be reduced by considerably increased the green spaces of the community. Unfortunately, given the facts that the options of expanding green space were limited for most communities in Beijing, it was not practical to resolve storm runoff and flooding by this approach alone.

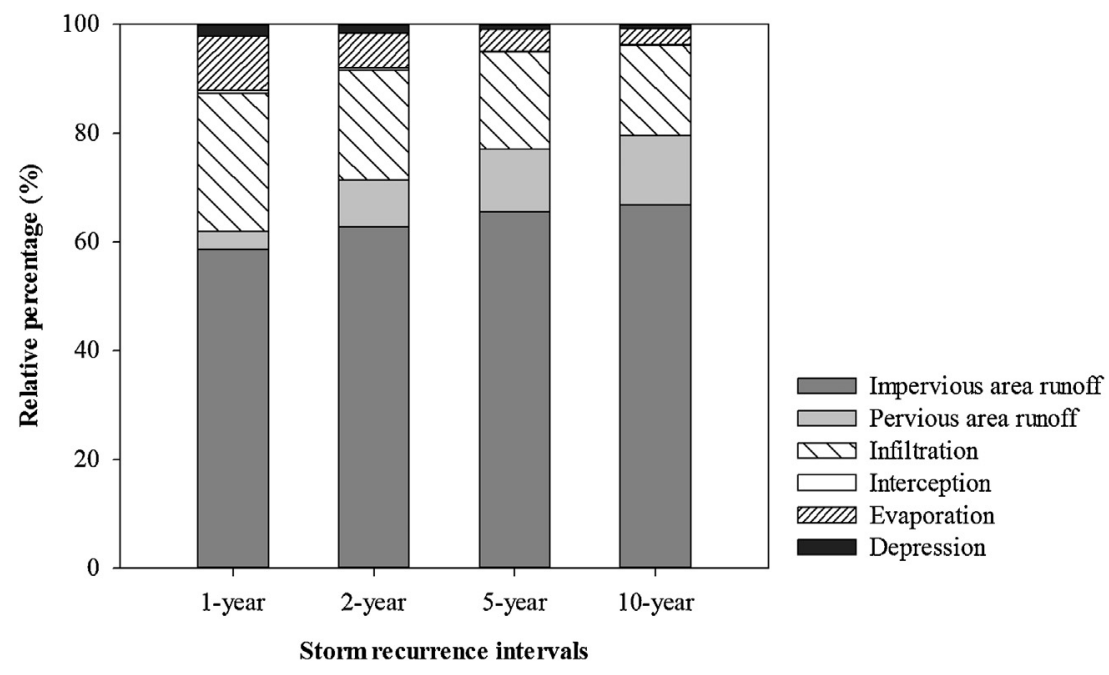

Fig. 4. The relative percentage figure for mass balance of rainfall-runoff process. 

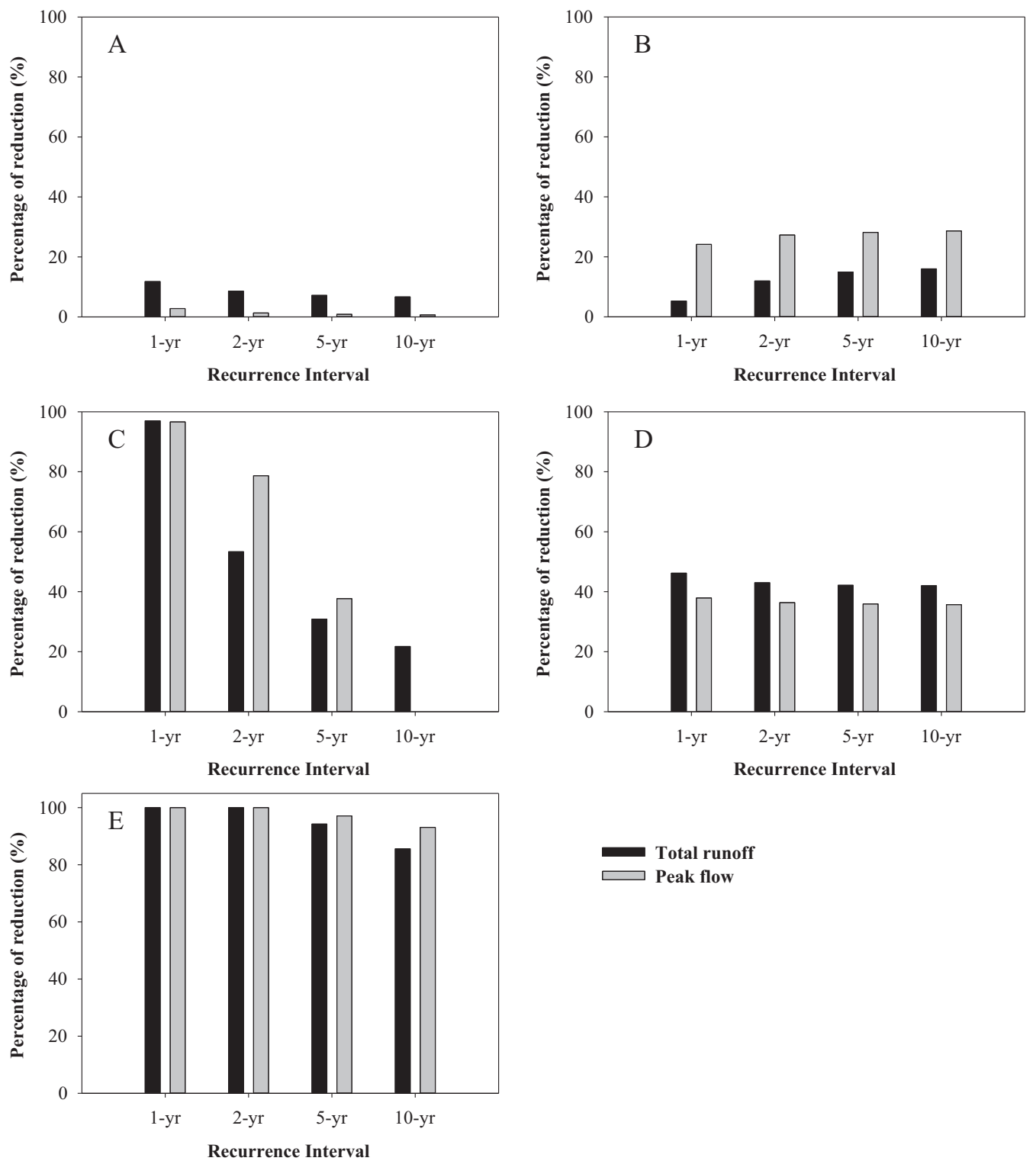

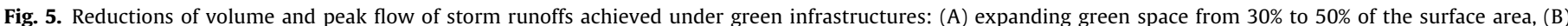

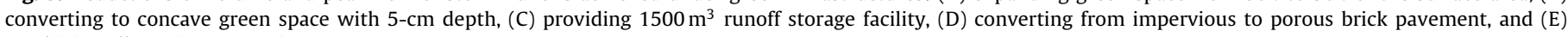
combining all previous scenarios.

\subsubsection{Concave green space}

The ground surface of urban green spaces in China usually is convex and higher than the surrounding roads. As a result, the storm water drains of the pervious green space and spills on to the impervious road surfaces easily became runoffs. If the ground surface of green spaces was shaped in concave form, the storm water would be prevented from flowing to the impervious road surfaces. We assumed the existing green spaces of the community were reshaped with a depth of $5 \mathrm{~cm}$. Comparing to the base scenario, there would be no outflow from the concave green space. The runoff volumes reduced $5.3-16.0 \%$ respectively under $1-, 2-, 5-$, and 10-year storm events. The peak flows were 35.9, $71.2,94.2$ and $108.7 \mathrm{~m}^{3} / \mathrm{min}$ that reduced $24.2-28.6 \%$ respectively under 1-, 2-, 5-, and 10-year storm events (Fig. 5B). The concave shaped green space would temporarily store the storm water and allow it to infiltrate over time, consequently increase groundwater recharge. The implementation would maximize the infiltration capacity of the green space. If the flat or raised green spaces are changed to be concave to increase infiltration and retain partial impervious runoff, the ecological function in terms of storm runoff reduction, infiltration and groundwater recharge would be greatly enhanced.

\subsubsection{Storage pond}

The storage pond may be constructed to capture the storm water thus reduce the runoff. Comparing to the base scenario, installing $1500 \mathrm{~m}^{3}$ of runoff storage capacity, reduced the runoff volumes by $97.0 \%, 53.3 \%, 30.9 \%$, and $21.8 \%$. Meanwhile, the peak flows were 1.6 , $20.9,81.7$ and $152.4 \mathrm{~m}^{3} / \mathrm{min}$, reduced $96.6 \%, 78.7 \%, 37.7 \%$, and $0 \%$, respectively, under 1-, 2-, 5-, and 10-year storm events (Fig. 5C). The results implied that the flooding reductions of storage pond were effective in small storms, but ineffective in large storms.

For a storm of 1-year recurrence interval, almost all of the storm water of the community may be retained in the storage pond. To contain the whole runoff discharge, the storage capacity must reach at least $1547.0,2813.3,4858.0$, and $6,894.8 \mathrm{~m}^{3}$, respectively, for the recurrence intervals of 1-, 2-, 5-, and 10-year. There is a serious water shortage in Beijing. The stored (harvested) storm water could be used in the community for green land irrigation, toilet flushing, and car washing. If the majority of communities 
implemented the storage facilities (i.e., the decentralized, small sized cisterns and tanks, and underground storage ponds) to harvest rainwater for non-potable uses, water scarcity and flooding problem in Beijing will be partly mitigated. Many communities in Beijing have adopted this green infrastructure and proved to be effective. In practice, adoption of storage facilities is depended on the communities' space and the potential uses of harvested rainwater. Given that the high cost of potable water in Beijing, the storm water storage facilities were cost effective and should be encouraged in communities for sustainable water management.

\subsubsection{Porous pavement}

The impervious surface can be replaced with porous brick pavement to decrease runoff generation. The infiltrate rate of permeable brick far exceeds the intensities of ordinary rains allowing the storm water stored in the cushion layer and then gradually infiltrate into soil strata below. If $50 \%$ of impervious surfaces were converted into porous brick pavements, the runoff volumes were reduced $46.2-42.0 \%$, and the peak flows were reduced $37.9-35.7 \%$, respectively under 1-, 2-, 5-, and 10-year storm events (Fig. 5D). If all the impervious areas except for the rooftop area (accounting for $20 \%$ of the community's footprint) were replaced by porous pavement, the runoff volumes and peak flows could reduce $66.5-59.6 \%$ and $54.2-51.0 \%$, respectively, under the storm recurrence intervals.

The porous brick pavements were more effective to reduce the storm runoffs than increasing green spaces or converting to concave shape green spaces, because the runoffs from impervious area account for more than half of the total runoff. Converting the impervious surfaces to pervious surfaces effectively reduced the runoffs from impervious surfaces. In Beijing, impervious surfaces such as parking lots, roads, courtyards, and public squares were found throughout the most communities. They leaded to large runoff volumes and high peak flows exasperating the flooding and even traffic jams. Converting them to permeable surfaces would significantly reduce the impervious runoff and improve current situations.

\subsubsection{Integrated approach}

Model simulation results illustrated that a single green infrastructure approach was not capable of effectively reducing both the runoff volume and peak flow. The storage pond was highly effective at controlling the volume and peak flow of runoff of 1-year recurrence interval storm, however its storage capacity was inflexible and extremely limited. In urban communities, there was little spare room to retrofitting a runoff storage facility with adequate capacities. Therefore, single GI facility cannot be feasibly and effectively performed to control urban flooding. Options of integrated green infrastructures were imperative to minimize the impacts of storm runoffs. If we incorporated all of the previously examined green infrastructures, the storm water runoff of the 1- and 2-year recurrence intervals was completely eliminated and volume and peak flow of storm runoffs of 5- and 10-year recurrence interval storm runoffs reduced by $94.2 \%$ and $85.6 \%$, and $97.1 \%$ and $93.1 \%$, respectively (Fig. 5E). The GI integration reduced significantly both the volume and peak flow of storm runoffs. The reduction effectiveness was more than $85 \%$. In this manner, the community essentially does not have a need of discharging storm runoffs. The integration of GI facilities enhanced the reduction effectiveness under different storms. Therefore, implementing the integrated GI facilities in communities may have considerable contribution to urban flooding control. Besides, it increased rainwater infiltrated into soil, stored and utilized the storm water resources that saved the water consumption in the community. The integrated GI implemented throughout communities would maintain the urban ecosystem's hydrologic and ecological functions, and allow water resources to be maintained that provide ecological sinks to mitigate environmental change.
Mentens et al. (2006) pointed out that a single green infrastructure alone will never fully eliminate the urban runoff and it needs to be combined with other runoff reduction measures. The outcomes of model simulation illustrate how runoff reduction measures should be integrated to optimize the effectiveness of flooding reduction. The reduction effectiveness of GI implementing in other communities such as the older ( $10 \%$ pervious percentage) and villa (50\% pervious percentage) communities will have linear changes due to the different contribution of impervious/pervious area to the total runoff.

\section{Conclusions}

Rapid urbanization has dramatically increased the volume and peak flow of storm runoffs that exposing communities to greater risks of flood hazards. Climate change further increased the extremities of precipitation events leading to higher frequencies and intensities of floods. The green infrastructures softened the impacts of urban runoffs and helped to retain water in urban ecosystems. Increasing green spaces, reducing impervious surfaces, and building storm water retention facilities can ease the deleterious impacts brought by the rapid urbanization. After the GI practices applied on a broad scale, it will enhance the ecological function of urban ecosystem, promote sustainable living and supports appropriate urban development.

Management tools that quantify how GI configuration influences storm runoff reduction were needed. We incorporate a few hydrological models' algorithms, and developed a simple model which can well address the functions of GI on the storm water reduction but with less parameters input. The simulated results showed the model performs in simulating storm water runoffs were responded to varying recurrence intervals. The outcomes of scenario simulations showed the effects of single GI facility on flooding reduction were limited under large storms. The integrated GI configurations were effectively reduced in all storm events. Therefore, in order to provide effective reductions for an entire spectrum of storm events to control urban flooding, a more effective strategy would be to implement integrated GI facilities. Reform or planning urban landscape with appropriate green infrastructure practices throughout communities is important for healthy and sustainable development.

\section{Acknowledgements}

We are thankful for the financial support of the National Natural Science Foundation of China (\#41271501) and the National Science \& Technology Pillar Program during the Twelfth Five-year Plan Period (\#2012BAC13B04) to this research.

\section{References}

Ahiablame, L.M., Engel, B.A., Chaubey, I., 2012. Effectiveness of low impact development practices: literature review and suggestions for future research. Water Air Soil Pollut. 223 (7), 4253-4273, http://dx.doi.org/10.1007/s11270-012-1189-2.

Alfredo, K., Montalto, F., Goldstein, A., 2009. Observed and modeled performances of prototype green roof test plots subjected to simulated low-and high-intensity precipitations in a laboratory experiment. J. Hydrol. Eng. 15 (6), 444-457, http://dx.doi.org/10.1061/(ASCE)HE. 1943-5584.0000135.

Benedict, M.A., McMahon, E.T., 2002. Green infrastructure: smart conservation for the 21 st century. Renew. Resour. J. 20 (3), 12-17, Retrieved from http://www.sprawlwatch.org/greeninfrastructure.pdf

Benedict, M.A., McMahon, E.T., 2006. Green Infrastructure: Linking Landscapes and Communities. Island Press.

Bettencourt, L., West, G., 2010. A unified theory of urban living. Nature 467 (7318), 912-913, http://dx.doi.org/10.1038/467912a.

Chapman, C., Horner, R.R., 2010. Performance assessment of a streetdrainage bioretention system. Water Environ. Res. 82 (2), 109-119, http://dx.doi.org/10.2175/106143009X426112. 
Chen, S.Q., Chen, B., Fath, B.D., 2014. Urban ecosystem modeling and global change: potential for rational urban management and emissions mitigation. Environ. Pollut. 190, 139-149, http://dx.doi.org/10.1016/j.envpol.2014.03.032.

Chen, S.Q., Chen, B., Fath, B.D., 2013. Ecological risk assessment on the system scale: a review of state-of-the-art models and future perspectives. Ecol. Model. 250, 25-33, http://dx.doi.org/10.1016/j.ecolmodel.2012.10.015.

Dreelin, E.A., Fowler, L., Ronald Carroll, C., 2006. A test of porous pavement effectiveness on clay soils during natural storm events. Water Res. 40 (4), 799-805, http://dx.doi.org/10.1016/j.watres.2005.12.002.

Droogers, P., Allen, R.G., 2002. Estimating reference evapotranspiration under inaccurate data conditions. Irrig. Drainage Syst. 16 (1), 33-45, http://dx.doi.org/10.1023/A:1015508322413.

Dunn, A.D., 2010. Siting green infrastructure: legal and policy solutions to alleviate urban poverty and promote healthy communities. BC Envtl. Aff. L. Rev. 37, 41.

Ferguson, B.K., 1998. Introduction to Stormwater: Concept, Purpose, Design. Wiley Com.

Foster, J., Lowe, A., Winkelman, S., 2011. The Value of Green Infrastructure for Urban Climate Adaptation. Center for Clean Air Policy, February. Retrieved fromhttp://ccap.org/assets/The-Value-of-Green-Infrastructure-for-Urban-ClimateAdaptation_CCAP-Feb-2011.pdf

Fu, S.H., Liu, B.Y., Wu, J.D., Duan, S.H., 2002. Study on runoff calculation method in Beijing mountainous area. Dili Kexue (Scientia Geographica Sinica) 22 (5), 604-609 (in Chinese).

Graham, P., Maclean, L., Medina, D., Patwardhan, A., Vasarhelyi, G., 2004. The role of water balance modeling in the transition to low impact development. Water Qual. Res. J. Ca 39 (4), 331-342, Retrieved from- https://www.cawq.ca/journal/ temp/article/121.pdf

Gill, S.E., Handley, J.F., Ennos, A.R., Pauleit, S., 2007. Adapting cities for climate change: the role of the green infrastructure. Built Environ. 33 (1), 115-133, http://dx.doi.org/10.2148/benv.33.1.115.

Goonetilleke, A., Thomas, E., Ginn, S., Gilbert, D., 2005. Understanding the role of land use in urban stormwater quality management. J. Environ. Manage. 74 (1), 31-42, http://dx.doi.org/10.1016/j.jenvman.2004.08.006.

Hargreaves, G.H., Samani, Z.A., 1985. Reference crop evapotranspiration from ambient air temperature. Am. Soc. Agric. Eng. 1 (2), 96-99.

Huber, W.C., Dickinson, R.E., Barnwell Jr., T.O., Branch, A., 1988. Storm water management model, version 4. Environ. Protect. Agency 600, 3-88, Retrieved from http://eng.odu.edu/cee/resources/model/mbin/swmm/swmm_1.pdf

Lei, X.H., Jiang, Y.Z., Wang, H. (Eds.), 2010. The Distributed Hydrological Model of EasyDHM. China WaterPower Press, Beijing (in Chinese).

Linsley, R.K., Kohler, M.A., Paulhus, J.L., 1949. Applied Hydrology. McGraw-Hill, New York.
Mein, R.G., Larson, C.L., 1973. Modeling infiltration during a steady rain. Water Resour. Res. 9 (2), 384-394, http://dx.doi.org/10.1029/WR009i002p00384.

Mell, I.C., 2009. Can green infrastructure promote urban sustainability? Proceedings of the ICE-Engineering Sustainability 162 (1), 23-34, http://dx.doi.org/ 10.1680/ensu.2009.162.1.23.

Mentens, J., Raes, D., Hermy, M., 2006. Green roofs as a tool for solving the rainwater runoff problem in the urbanized 21st century? Landsc. Urban Plann. 77 (3), 217-226, http://dx.doi.org/10.1016/j.landurbplan.2005.02.010.

Mitchell, V., Diaper, C., Gray, S.R., Rahilly, M., 2003. UVQ: modelling the movement of water and contaminants through the total urban water cycle. In: Paper presented at the 28th International Hydrology and Water Resources Symposium: About Water; Symposium Proceedings.

MUSIC Development Team, 2003. MUSIC User Guide Version 2. 0. Cooperative Research Centre for Catchment Hydrology, Melbourne, Australia.

Qin, H.-p., Li, Z.-X., Fu, G., 2013. The effects of low impact development on urban flooding under different rainfall characteristics. J. Environ. Manage. 129, 577-585, http://dx.doi.org/10.1016/j.jenvman.2013.08.026.

Schneider, L.E., McCuen, R.H., 2006. Assessing the hydrologic performance of best management practices. J. Hydrol. Eng. 11 (3), 278-281, http://dx.doi.org/10.1061/(ASCE)1084-0699(2006)11:3(278).

Su, F., Xie, Z., 2003. A model for assessing effects of climate change on runoff in China. Progr. Nat. Sci. 13 (9), 701-707, http://dx.doi.org/10.1080/ 10020070312331344270.

Villarreal, E.L., Semadeni-Davies, A., Bengtsson, L., 2004. Inner city stormwater control using a combination of best management practices. Ecol. Eng. 22 (4), 279-298, http://dx.doi.org/10.1016/j.ecoleng.2004.06.007.

Wang, X.X., 2007. Assessing the runoff intercepting capacity of greenbelts of different underlying surfaces in residential district. In: Thesis of China Agricultural University, Beijing (in Chinese)

Wang, J., Endreny, T.A., Nowak, D.J., 2008. Mechanistic simulation of tree effects in an urban water balance model1. JAWRA J. Am. Water Resour. Assoc. 44 (1), 75-85, http://dx.doi.org/10.1111/j. 1752-1688.2007.00139.x.

White, R., 2002. Building the Ecological City. CRC Press.

Whitford, V., Ennos, A.R., Handley, J.F., 2001. 'City form and natural process'-indicators for the ecological performance of urban areas and their application to Merseyside, UK. Landsc. Urban Plann. 57 (2), 91-103, http://dx.doi.org/10.1016/S0169-2046(01)00192-X.

Xie, Y., Huang, G., Zhao, L., 1998. Spatial variability of field soil properties. Zhongguo Nongyedaxue Xuebao (J. China Agric. Univ.) 3 (2), 41-45 (in Chinese).

Xu, X., 1998. Simulation of storm runoff process for plain urban. Shuili Xuebao (J. Hydraulic Eng.) 8 (8), 34-37 (in Chinese). 